\title{
Reliability and Validity of the Abbreviated Turkish Version of the Zarit Caregiver Burden Interview
}

\section{Gülsen BABACAN YILDIZ1', Ömer YACI², Zeynep AKÇA3, Ișın Baral KULAKSIZOĞLU² \\ ${ }^{1}$ Department of Neurology, Bezmialem Vakıf University School of Medicine, İstanbul, Turkey \\ ${ }^{2}$ Department of Psychiatry, Bezmialem Vakıf University School of Medicine, İstanbul, Turkey \\ ${ }^{3}$ Department of Psychology, Bezmialem Vakıf University School of Medicine, İstanbul, Turkey}

\section{ABSTRACT}

Objective: Our aim was to validate the Turkish version of the 12-item form of the Zarit Caregiver Burden Interview (T-ZBI-12) as an instrument to measure the caregiver burden in caregivers of patients with dementia in Turkey and to evaluate its reliability.

Methods: A total of 90 caregivers of Alzheimer's patients with dementia from two outpatient clinics were included in the study. MMSE was used to determine dementia severity, and validity was examined using the correlation between the T-ZBI-12 and MMSE score. We used item-total correlations to check whether there was an item inconsistent with the rest of the interview.

Results: The abbreviated scale (T-ZBI-12) is valid and reliable, with a Cronbach's alpha value of 0.92. All item-total correlations were significant $(\mathrm{p}<0.01)$. The results demonstrated good validity, with significant correlations between caregiver burden and dementia severity.

Conclusion: T-ZBI-12 is reliable and valid for the assessment of dementia caregiver burden in Turkey.

Keywords: Alzheimer, caregiver, Zarit Caregiver Burden

\section{Introduction}

With the growing elderly population, there is a significant increase in the number of patients with dementia as well as caregiving problems worldwide, including Turkey (1-3).

Alzheimer's disease (AD) is the most common type of dementia. As the number of patients increases, caregiver burden emerges as another important and serious public health concern. Although Turkey is a developing country, because of the increasing life expectancy, the prevalence rate of $\mathrm{AD}$ is higher than that in developed countries (4).

Caregiving is a multifactorial concept and includes physical, social, financial, and emotional components. All these components have a negative effect on caregivers of patients with dementia (5-7). In clinical settings, the caregiver plays an important role in the treatment of patients with dementia. Therefore, knowledge about and objective evaluation of caregiver burden are essential to reduce, encourage, and prevent psychiatric comorbidities such as depression and anxiety disorders. Thus, the presence of a convenient support corresponds to lower levels of caregiver burden and help to improve the quality of life of both patients and caregivers. There are many ways to measure caregiver burden (8, 9). However, the most widely used instrument for the assessment of caregiver burden is the Zarit Caregiver Burden Interview (ZBI) $(10,11)$ owing to its high internal consistency and good test-retest reliability (12).

The aim of this study was to validate the Turkish version of the 12-item form of ZBI (T-ZBI-12) to measure dementia caregiver burden in caregivers of patients with $\mathrm{AD}$ in Turkey and to evaluate its reliability. 


\section{Methods}

Because the translated version of ZBI was understood and interpreted similarly to the original tool, the back-translation method was used for the translation of ZBI-12 into Turkish in this prospective study. At the first stage, the original ZBI-12 was translated into Turkish and back-translated by a professional bilingual translator. Finally, the back-translated version was compared with the original one. To test language issues, the Turkish version of T-ZBI-12 was administered to a small, independent sample group for 4 months.

Ninety consecutive patients suffering from $\mathrm{AD}$ dementia and their 90 caregivers were recruited from the Department of Psychiatry and the Neurology Department (Behavioral Neurology and Movement Disorders Unit) at the Istanbul School of Medicine, Istanbul University, to validate T-ZBI-12. Exclusion criteria included diseases noted in the patient's history, which influence caregiver burden. For this purpose, the caregivers were asked whether the patient had experienced a series of health problems, including serious chest problems, heart condition, kidney disease, cancer, uncontrolled diabetes and high blood pressure, arthritis, and serious orthopedic inquiries. The caregivers of the patients were informed about the nature and aim of the study, and written informed consent was obtained. The study was approved by the Ethics Committee of İstanbul University.

The interview was administered once to the caregivers by a neurologist (G.B.Y.), psychiatrist (O.Y.), or psychologist (Z.A.) face to face in the outpatient clinics.

\section{ZBI}

Zarit et al. (10) developed ZBI to assess the level of burden reported by caregivers of patients with dementia. The original version published in 1980 included 29 items. In 1985, the version based on 22 items evolved from the first version (13), and it is still most commonly used for the measurement for caregiver burden in the United States and in European countries (14). Each item is rated on a 5-point Likert scale from 0 (never) to 4 (nearly always). ZBI is a self-administered questionnaire. The questions are about the relationship between the caregiver and patient as well as the caregiver's health status, psychological well-being, social life, and financial status. ZBI-22 has been translated to many languages, and the internal consistency ranges from 0.85 to 0.94 (15). In its 22 item version, the highest score is 88 and lowest score is 0 . A higher score indicates a higher caregiver burden. There are different cut-off scores indicating the level of burden. Total scores over 61 are defined as severe, between 41 and 60 as moderate, between 21 and 40 as mild, and below 21 as little or no burden (16).

\section{Shorter versions of ZBI}

There are many different versions of ZBI. To determine the subjective domain of caregiver burden within as less time as possible, many shorter versions of ZBI (ZBI-12, ZBI-8, ZBI-
7, ZBI-6, ZBI-4, and ZBI-1) have been developed, with 3 of them (ZBI-12, ZBI-8, and ZBI-4) being most commonly used. All the shorter versions have been reported to be successful in distinguishing between low- and high-burden individuals (17). The 12 -item version has been reported to be the most appropriate with a cutoff score of 12 (17-19).

\section{Caregiver and patient data collection}

Caregivers are defined as persons providing day-to-day care to patients. To determine the primary caregivers' socio-demographic status, we collected caregiver information, including age, gender, and kin relationship.

The Mini-Mental State Examination (MMSE), a well-known brief screening scale for global cognitive status, is widely used worldwide (20). The maximum score is 30 points, and a lower score means a higher cognitive impairment and greater dementia severity. To determine the level of global cognitive function in the patients, we used MMSE and characterized dementia severity as mild (MMSE score between 21 and 26), moderate (MMSE score between 10 and 20), and severe (MMSE score < 10).

\section{Psychometric Evaluation}

Validity was examined using the correlation between the TZBI-12 total score and MMSE score, as reported previously (21). To evaluate reliability, internal consistency was assessed using Cronbach's alpha coefficient and item-total correlation for checking whether there was an item inconsistent with the rest of the interview.

\section{Statistical analysis}

Statistical analysis was performed using the Statistical Package for the Social Sciences (SPSS Inc.; Chicago, IL, USA) statistics 15.0 version. Because the answers given to the questions in ZBI were Likert type, Cronbach's alpha coefficient was used to determine the internal consistency. A p value of less than 0.05 was considered statistically significant.

\section{Results}

T-ZBI-12 was administered to all the caregivers, $77.8 \%$ of whom were women, aged from 22 to 78 (mean: 53.77) years. In total, $30 \%$ of caregivers were spouses of the patients, $50 \%$ were daughters, $11.1 \%$ were sons, $6.7 \%$ were daughters-inlaw, and $1.1 \%$ were siblings, while $1.1 \%$ were formal caregivers. The minimum/maximum values and standard deviations are listed in Table 1.

The Cronbach's alpha value for the T-ZBI-12 items was 0.92 . The item-total correlations were all significant $(\mathrm{p}<0.01)$.

As shown in Table 2, the mean T-ZBI-12 score was $14.41 \pm 10.22$ (minimum: 0; maximum: 38).

The patients' average MMSE score was $14.67 \pm 7.3$ (minimum: 0; maximum: 26). For each dementia stage, there were 30 patients suffering from mild (mean score: $22.53 \pm 1.76$; 


\begin{tabular}{|c|c|c|}
\hline Patients characteristics & Mean \pm SD (min-max) & $\%(n=90)$ \\
\hline Age & $74.54 \pm 8.375(53-92)$ & \\
\hline Gender & & $\begin{array}{c}33 \mathrm{~F}, 57 \mathrm{M} \\
36.7 \% \mathrm{~F} \\
63.3 \% \mathrm{M}\end{array}$ \\
\hline MMSE score & $14.67 \pm 7.31(0-26)$ & \\
\hline$>20$ & $22.53 \pm 1.76(20-26)$ & \\
\hline $10-20$ & $15.63 \pm 2.13(12-19)$ & \\
\hline$<10$ & $5.83 \pm 3.24(0-9)$ & \\
\hline Caregiver characteristics & & \\
\hline Age & $53.77 \pm 12.9(22-78)$ & \\
\hline Gender & & $\begin{array}{c}70 \mathrm{~F}, 20 \mathrm{M} \\
77.8 \% \mathrm{~F} \\
22.2 \% \mathrm{M}\end{array}$ \\
\hline T-ZBI-12 & $14.41 \pm 10.22(0-38)$ & \\
\hline Kin relationship & & \\
\hline Spouse & & $30 \%(27)$ \\
\hline Daughter & & $50 \%(45)$ \\
\hline Son & & $11.1 \%(10)$ \\
\hline Daughter-in-law & & $6.7 \%(6)$ \\
\hline Sibling & & $1.1 \%(1)$ \\
\hline Formal & & $1.1 \%(1)$ \\
\hline
\end{tabular}

MMSE: mini-mental state examination; F: female; M: male; T-ZBI-12: the Turkish version of the 12 -item form of the zarit caregiver burden interview

minimum: 20, maximum: 26), moderate (mean score: $15.63 \pm 2.13$; minimum: 12 , maximum: 19 ), and severe (mean score 5.83 \pm 3.24 , minimum: 0, maximum: 9) dementia. The T-ZBI-12 score negatively correlated with the MMSE score (Pearson's correlation coefficient: -0.29 , p<0.01).

\section{Discussion}

As in many other countries worldwide, Turkey has a high prevalence rate of AD because of increased life expectancy (4). Because $\mathrm{AD}$ has a negative impact on patients and individuals providing care to them and as the Turkish population ages, the number of caregivers will increase.

Unlike the United States and European countries, a limited number of patients with AD stay in nursing homes in Turkey. To institutionalize an elderly family member with dementia is not socially well-accepted, and patient care is usually provided by a family member (22). Caregiving is stressful; therefore, caregivers may experiencephysical, personal, social, financial, and emotional difficulties, and consequently, depression and anxiety $(23,24)$. Determining caregiver burden is crucial to protect their physical and mental health.

A validated, easy, and quick test is necessary to determine the degree of caregiver burden in crowded outpatient clin- ers with problems will give us the opportunity to help them overcome the difficulties experienced. We aimed to validate T-ZBI-12 for objective evaluation of caregiver burden. All item-total correlations were statistically significant $(p<0.01)$ with high internal consistency (Cronbach's alpha: 0.92). This means that T-ZBI-12 is a valid instrument to assess dementia caregiver burden. The internal consistency of T-ZBI-12 was identical to that reported by Hebert, who proposed a shorter version based on 12 items and compared it with the original version $(10,12)$. The mean T-ZBI-12 score was also comparable with that reported by other validation studies $(11,17)$. Besides being a short screening tool, T-ZBI-12 gave results similar those of the full version for use in caregivers of $\mathrm{AD}$ patients.

In addition, T-ZBI-12 is very relevant for researchers and clinicians in Turkey as well as in some other European countries with a high percentage of Turkish migrants. Patients with dementia require a great deal of care. As the disease progresses, caregiving burden increases, especially depending on the patient's dependency for activities of daily living and their neuropsychiatric symptoms $(25,26)$. We found a statistically significant relationship between caregiver burden and severity of dementia, i.e., a higher T-ZBI-12 score indicated a higher disease stage. Our results confirmed the findings of previous studies, demonstrating a negative influence of dementia, which is associated with severe caregiver burden $(21,27)$. Undoubtedly, behavioral symptoms are important factors that increase caregiver burden. However, we aimed to concentrate on leaner validation using only correlations between caregiver burden and dementia severity. Hence, our results indicated that the use of T-ZBI-12 was adequate to measure caregiver burden, regardless of the presence or absence of behavioral symptoms in patients with dementia.

It is thought that the degree of perceived caregiver burden may change depending on gender, age, and kin relationship. However, we found no significant differences between the abovementioned factors and T-ZBI-12 scores; this is attributable to the cultural structure of the Turkish population.

We know that caregiver burden has an unfavorable influence on the psychological and physical status of caregivers. However, difficulties faced by caregivers and the perceptions of caregiver burden may vary between different cultures. Because institutionalization of patients with dementia is unacceptable and a social stigma according to the Turkish culture, the provision of care for the elderly is regarded as an obligation for family members. This responsibility is often given to the spouse or daughter, who is usually not ready for the role. In the present study, we found that the proportion of caregivers other than family members was only $1.1 \%$.

\section{Conclusion}

Finally, T-ZBI-12 employed in our study is reliable and valid to be used for the measurement of dementia caregiver burden. 
Table 2. Item-total correlation

\section{Item}

1. Do you feel that your patient asks for more help than he/she needs?

2. Do you feel that because of the time you spent with your patient, you don't have enough time for yourself?

3. Do you feel stressed between caring for your patient and trying to meet other responsibilities for your family or work?

4. Do you feel embarrassed about your patient's behavior?

5. Do you feel angry when you are around your patient?

6. Do you feel that your patient affects your relationship with other family members or friends in a negative way?

7. Are you afraid of what the future holds for your patient?

8. Do you feel that your patient is dependent on you?

9. Do you feel strained when you are around your patient?

10. Do you feel that your health has suffered because of your involvement with your patient?

11. Do you feel that you don't have as much privacy as you would like because of your patient? 12. Do you feel that your social life has suffered because you are caring for your patient?
Mean \pm SD

Item-total correlation

$\begin{array}{ll}1.62 \pm 1.31 & 0.66 \\ & 0.73 \\ 1.42 \pm 1.15 & \\ & 0.60 \\ 0.86 \pm 0.90 & 0.68 \\ 1.03 \pm 1.20 & 0.71 \\ 1.21 \pm 1.16 & \\ & 0.74 \\ 0.96 \pm 1.12 & 0.85 \\ 1.36 \pm 1.31 & 0.83 \\ 1.3 \pm 1.24 & 0.77 \\ 0.94 \pm 1.20 & 0.49 \\ 1.22 \pm 1.05 & 0.25 \\ 1.74 \pm 1.41 & 0.62 \\ 0.74 \pm 1.00 & \end{array}$

The responsibilities of clinicians and researchers are not only toward patients but also toward their caregivers who are at increased risk of physical and emotional problems. Therefore, our study highlights the importance of evaluating caregiver burden and providing more appropriate support to caregivers.

Ethics Committee Approval: Ethics committee approval was received for this study from Ethics Committee of Istanbul University.

Informed Consent: Written informed consent was obtained from patients who participated in this study.

Peer-review: Externally peer-reviewed.

Author Contributions: Concept - G.B.Y., I.B.K.; Design - G.B.Y., I.B.K.; Supervision - G.B.Y., I.B.K.; Funding - G.B.Y., I.B.K., O.Y., Z.A.; Materials - G.B.Y., O.Y., Z.A.; Data Collection and/or Processing - G.B.Y., I.B.K., O.Y., Z.A.; Analysis and/or Interpretation - G.B.Y., I.B.K., O.Y.; Literature Review - G.B.Y.; Writing - G.B.Y.; Critical Review - G.B.Y., I.B.K.; Other - G.B.Y., I.B.K., O.Y., Z.A.

Acknowledgments: We are grateful to the patients and their caregivers for participating in our study.

Conflict of Interest: No conflict of interest was declared by the authors.

Financial Disclosure: The authors declared that this study has received no financial support.

\section{References}

1. Gungen C, Ertan T, Eker E, Yaşar R, Engin F. Reliability and validity of the standardized Mini Mental State Examination in the diagnosis of mild dementia in Turkish population. Turk Psikiyatri Derg 2002; 13: 273-81.
2. Sahin EM, Yalçın BM. Huzurevinde veya kendi evlerinde yaşayan yaşlılarda depresyon sıklıklarının karşılaştırması. Turkish Journal of Geriatrics 2003; 6: 10-3.

3. Hirtz D, Thurman DJ, Gwinn-Hardy K, Mohamed M, Chaudhuri AR, Zalutsky R. How common are the "common" neurologic disorders? Neurology 2007; 68: 326-37. [CrossRef]

4. Gurvit H, Emre M, Tinaz S, Bilgic B, Hanagasi H, Sahin H. The Prevalence of Dementia in an Urban Turkish Population. Am J Alzheimers Dis Other Demen 2008; 23: 67-76. [CrossRef]

5. Baumgarten M, Battista RN, Infante-Rivard C, Hanley JA, Becker R, Gauthier S. The psychological and physical health of family members caring for an elderly person with dementia. Journal of Clinical Epidemiology 1992; 45: 61-70. [CrossRef]

6. Given B, Kozachik S, Collins $\mathrm{C}$ et al. Caregiver role strain. In: Maas M, Buckwalter K, Hardy M, Tripp-Reimer T, Titler M (eds) Nursing Care of Older Adult Diagnoses: Outcome and Interventions. Mosby, St. Louis, MO 2001; 679-680.

7. Grov EK, Dahl A, Moum T, Fosså SD. Anxiety, depression, and quality of life in caregivers of patients with cancer in late palliative phase. Ann Oncol 2005; 16: 1185-91. [CrossRef]

8. Vitaliano PP, Young HM, Russo J. Burden: a review of measures used among caregivers of individuals with dementia. Gerontologist 1991; 31: 67-75. [CrossRef]

9. Kinsella G, Cooper B, Picton C, Urtagh D. A review of the measurement of caregiver and family burden in palliative care. $\mathrm{J}$ Palliative Care 1998; 14: 37-45.

10. Zarit SH, Reever KE, Bach-Peterson J. Relatives of the impaired elderly: Correlates of feelings of burden. Gerontologist 1980; 20: 649-55. [CrossRef]

11. Bédard M, Pedlar D, Martin N. Burden in caregivers of cognitively impaired older adults living in the community: Methodological issues and determinants. International Psychogeriatrics 2000; 12, 307-32. [CrossRef]

12. Hébert R, Bravo G, Préville M. Reliability, validity and reference values of the Zarit Burden Interview for assessing informal 
caregivers of community-dwelling older persons with dementia. Canadian Journal on Aging 2000; 19; 494-507. [CrossRef]

13. Zarit SH, Orr NK, Zarit JM. The hidden victims of Alzheimer's disease: Families under stress. New York 1985; New York University Pres.

14. Arai Y. Family caregiver burden and quality of home care in the context of the long-term care insurance scheme: An overview. Psychogeriatrics 2006; 6: 134-8. [CrossRef]

15. Chichester JW, Baumgarten M. The health of persons giving care to the elderly: A critical review of the literature. Journal of Clinical Epidemiology 1989; 42: 1137-48. [CrossRef]

16. Zarit SH, Antony CR, Boutselis M. Interventions with caregivers of dementia patients: Comparison of two approaches. Psychology and Aging 1987; 2, 225-32. [CrossRef]

17. Higginson IJ, Gao W, Jackson D, Murray J, Harding R. Shortform Zarit Caregiver Burden Interviews were valid in advanced conditions. J Clin Epidemiol 2010; 63: 535-42. [CrossRef]

18. Bedard M, Molloy DW, Squire L, Dubois S, Lever JA, O'Donnell M. The Zarit Burden Interview: A new short version and screening version. Gerontologist 2001; 41: 652-7. [CrossRef]

19. O'Rourke N, Tuokko HA. Psychometric properties of an abridged version of The Zarit Burden Interview within a representative Canadian caregiver sample. Gerontologist 2003; 43: 121-7. [CrossRef]

20. Folstein M, Folstein S, McHugh P. 'Mini-Mental State': a practical method for grading the cognitive state of patients for the clinician. Journal of psychiatric research 1975; 12: 189-98. [CrossRef]

21. Braun M, Scholz U, Hornung R, Martin M. The burden of spousal caregiving: a preliminary psychometric evaluation of the German version of the Zarit burden interview. Aging Ment Health 2010; 14: 159-67. [CrossRef]

22. Atalay B, Konta YM, Beyazıt $S$ ve ark. Türk aile yapısı araştırması. Devlet Planlama Teskilatı. Yayın No: DPT 2313 SPGM. Ankara 1992; 421.

23. Moore MJ, Zhu CW, Clipp EC. Informal costs of dementia care: estimates from the national longitudinal caregiver study. J Gerontol B Psychol Sci Soc Sci 2001; 56: S219-28. [CrossRef]

24. Schulz R, Martire LM. Family caregiving of persons with dementia: prevalence, health effects, and support strategies. Am J Geriatr Psychiatry 2004; 12: 240-9. [CrossRef]

25. Perren S, Schmid R, Wettstein A. Caregivers' adaptation to change: The impact of increasing impairment of persons suffering from dementia on their caregivers' subjective well-being. Aging \& Mental Health 2006; 10: 539-48. [CrossRef]

26. Wijngaart MA, Vernooij-Dassen MJ, Felling AJ. The influence of stressors, appraisal and personal conditions on the burden of spousal caregivers of persons with dementia. Aging \& Mental Health 2007; 11: 626-36. [CrossRef]

27. Onishi J, SuzukiY, Umegaki H, Nakamura A, Endo H, Iguchi A. Influence of behavioural and psychological symptoms of dementia (BPSD) and environment of care on caregivers burden. Arch Gerontol Geriatr 2005; 41: 159-68. [CrossRef] 